\title{
Prosocial Behaviour and its Relevant Factors among Undergraduates
}

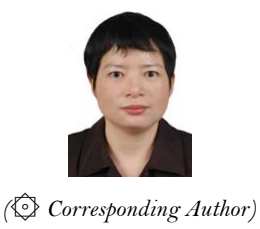

\author{
HOU Yongmei ${ }^{1}$ io \\ ZHENG Que ${ }^{2}$ \\ ZHENG Zhongyi ${ }^{3}$
}

${ }^{t, 2, s}$ Department of Psychology, School of Humanity and Administration, Guangdong Medical University, Guangdong Province, China.

'Email.2184456621@.gq.com

To explore the present status of prosociality among undergraduates and explore its major relevant factors. A stratified random sampling was used to select 1109 undergrauates from 10 full-time colleges in Guangdong province. They were investigated with Prosocial Tendencies Measure (PTM), Interpersonal Reactivity Index (IRI), Moral Disengagement Questionnaire (MDQ), Social Support

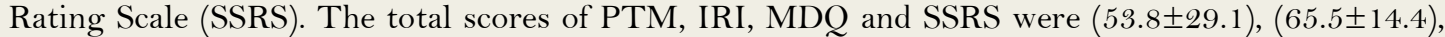
(39.4 \pm 10.2$)$ and (31.0 13.6$)$, respectively. The result of multiple stepwise linear regression showed that 10 factors, such as the total score of IRI, the total score of SSRS, nationality, religion, part time job, grade, origin, love experience, major category and gender, were postively related with the total score of PTM $(\beta=0.115$ to 0.708 , all $P<.05)$, family monthly income and the total score of MDQ were nagatively related with the total score of PTM $(\beta=-0.352, \quad-0.577$; both $P<.05)$. Conclusion Most of the undergraduates showed the intermedius level of prosocial behavior, which was closely related to such factors as family rearing, community cultural atmosphere, school education and the personality characteristics of the undergraduates.

Keywords: Undergraduates, Prosocial behavior, Status, Relevant factors, Questionnaire investigaion, Multiple stepreise linear Regression.

DOI: $10.20448 / 804.6 .1 .16 .27$

Citation | HOU Yongmei; ZHENG Que; ZHENG Zhongyi (2021). Prosocial Behaviour and its Relevant Factors among

Undergraduates. American Journal of Education and Learning, 6(1): 16-27.

Copyright: This work is licensed under a Creative Commons Attribution 3.0 License

Funding: This study received no specific financial support.

Competing Interests: The authors declare that they have no competing interests.

History: Received: 20 January 2021/ Revised: 24 February 2021/ Accepted: 18 March 2021/ Published: 12 April 2021

Publisher: Online Science Publishing 


\section{Highlights of this paper}

- $\quad$ Large sample and multi center survey mode was adopted.

- The quantitative research model of multiple linear regression was used.

- There is a comprehensive consideration of family, school, social and personal characteristics and other factors in our study.

\section{INTRODUCTION}

Prosocial behavior refers to a kind of behavior that actors voluntarily bring benefits to the recipients (others or society), including helping others, cooperation, sharing, politeness and so on (Eisenbe \& Miller, 1987). This kind of behavior usually needs to pay a certain cost or take certain risks, but it is of great significance to individual development and social harmony. Previous studies have shown that prosocial behavior helps individuals maintain positive emotions (Li \& Luo, 2013; Sun, Lin, \& Dai, 2017) improve academic (Wang \& Chen, 2003) and professional performance (Zhang \& Jia, 2013) create good interpersonal relationship (Wang \& Chen, 2003) enhance self-esteem and self-confidence (Antonio et al., 2014) cultivate psychological qualities such as innovation (Luan \& Chen, 2020) empathy (Li, Wang, \& Tian, 2018) and sense of responsibility (Li et al., 2018) reduce behavior problems such as aggression (Liang \& Hou, 2014) internet addiction (Mo, Yang, \& Xu, 2015) and promote social adaptation (Jin, Sun, \& Chen, 2013; Zheng \& Liu, 2013). Due to the great significance of prosocial behavior, it is increasingly concerned by all sectors of society.

At present, the advantage of College Students' prosocial behavior is manifested in reciprocity and public welfare, while the disadvantage is alienation of their prosocial behaviors (Xiu, 2018). Although the emergent prosocial behavior of college students is at higher level, their open prosocial behavior is at lower level (Zhang, 2013). Although college students are more willing to provide help, the time they are willing to provide help is relatively short, with an average of 15 to 20 minutes (Xia \& Li, 2016).

College students are in a critical period of personality stability. It is of great significance to clarify the present status and relevant factors of college students' prosocial behavior for cultivating prosocial ability and promoting the growth of high-quality talents.

Based on the above analysis, this study intends to explore the current status and related factors of college students' prosocial behavior by means of large sample and multi center survey.

\section{OBJECTS AND METHODS}

\subsection{Objects \\ 2.1.1. Sample Size Estimation}

The minimum sample size is calculated by $G *$ power 3 (Cohen, 1992). As PTM is used to evaluate the indicators related to mental health, and disease is one of the important indicators of mental health, we use the prevalence of mental illness of college students to calculate the sample size. Previous studies have shown that the prevalence of mental illness among college students is 9.0-27.7\% (Hu, 2012; Shi et al., 2013; Teng, 2017; Zhang \& Zhang, 2013; Zhong \& Li, 2009) and the test effect value is medium level (Hu, 2012; Shi et al., 2013; Teng, 2017; Zhang \& Zhang, 2013; Zhong \& Li, 2009) that is, the $\mathrm{d}$ value is 0.50 to 0.80 (Zhang \& Xu, 2012). In this study, we set the effect value $d=0.70$, the statistical test power of $1-\beta=0.80$, the type I error probability $\alpha=0.05$, and the minimum sample size is calculated as 678 . The minimum sample size is determined as 825 due to a $20 \%$ of possible follow-up loss rate. 


\subsubsection{Sampling}

From March to April, 2019, a total of 1200 questionnaires were distributed to college students from freshmen to fifth year from Guangdong Pharmaceutical University, Guangdong Medical University, Guangdong Academy of Fine Arts, Xinghai Conservatory of Music, Jinan University, Guangdong University of Finance \& Economics, Guangdong University of Foreign Studies, Dongguan University of Technology, Guangdong University of Technology and Shenzhen University by stratified random sampling. 1109 valid questionnaires were collected, with an effective rate of $92.4 \%$. Among them, there were 536 males and 573 females; 243 in comprehensive colleges, 304 in science and engineering colleges, 145 in liberal arts colleges, 197 in medical colleges, 95 in finance and economics colleges, 74 in sports colleges and 50 in art colleges; 231 freshmen, 219 sophomores, 225 juniors, 230 seniors, 204 fifth year students; 415 from cities, 330 from towns and 364 from countries.

2.2. Tools

2.2.1. prosocial Tendencies Measure, PTM

It is compiled by Carlo and Randall (2002) and revised by Cong (2008) into Chinese version. There are 23 questions, divided into six subscales: “open prosocial behavior (ONPB)”, “anonymous prosocial behavior” (ASPB), "altruistic prosocial behavior (ACPB)", "compliant prosocial behavior (CTPB)", "emotional prosocial behavior (ELPB)" and "emergent prosocial behavior (ETPB)". The Likert 5-point scoring method is used to score from 1 to 5 points corresponding to "not at all" to "completely yes". The higher the total score, the higher the degree of prosocial tendencies. In this study, the Cronbach's $\alpha$ coefficient of the total scale is 0.91 , and the Cronbach's $\alpha$ coefficient of each subscale is 0.82 to 0.87 .

\subsubsection{Interpersonal Reactivity Index, IRI}

It is compiled by Davis (1980) and revised into Chinese by Han, Ye, and Leng (2013). IRI has 22 items, divided into four dimensions: empathy and care (EC), fantasy (FS), perspective taking (PT), personal pain (PP). The 5-point scoring method is used to score from o to 4 points corresponding to "very inconsistent" to "very consistent". The higher the total score, the higher the empathy level. In this study, the cronbach'a coefficient of the total scale is 0.84, and the cronbach' $^{\prime}$ coefficient of each dimension is 0.69 to 0.78 .

\subsubsection{Moral Disengagement Questionnaire, MDQ}

Compiled by Bandura (1985) and revised by Lu (2015). There are 20 items, which are divided into four dimensions: moral defense (MD), favorable comparison(FC), responsibility attribution (RA) and responsibility disengagement (RD). The higher the total score, the higher the level of moral disengagement. In this study, the cronbach'a coefficient of the total scale is 0.89 , and the cronbach'a coefficient of each dimension is 0.72 to 0.85 .

\subsubsection{Social Support Rate Scale, SSRS}

Compiled by Xiao and Yang (1987), There are 10 items, divided into three dimensions: objective support (OS), subjective support (SS) and utilization of support (US). The higher the total score, the higher the level of social support. In this study, the cronbach' a coefficient of the total scale is 0.92 , and the cronbach' a coefficient of each dimension is 0.83 to 0.87 .

\subsubsection{Self-compiled Personal General Information Questionnaire}

The CNKI, Wanfang database, VIP database, Baidu, google, Pubmed and other search engines were used to search the literatures about the prosocial behavior among undergraduates (869 in Chinese and 7433 in foreign 
languages). Based on that, the basic content of the questionnaire was constructed, with a total of 19 items. Combined with the results of 3 collective discussions with 10 representatives of undergraduates and 5 experts in the field of higher education, 2 items were deleted and 1 item was added. The final questionnaire for personal general information involved 18 items, including age, grade, gender, origin, nationality, "Do you have any religious beliefs", "Are you or have you ever been a class cadre", "Are you working or have you ever worked part-time", school category, major category, academic performance, only-child or not, father's education level, mather's education level, father's occupation, mather's occupation, monthly household income, and “Are you or have you ever been in love" and so on.

\subsection{Data Manipulation}

SPSS 20.0 was used for statistical analysis. Descriptive statistics were used to calculate the average score and standard deviation of each scale; independent sample $t$-test, Pearson product correlation and one-way ANOVA were used to explore the correlation between variables; multiple stepwise linear regression was used to analyze the related factors of PTM total score.

\section{RESULT}

\subsection{Descriptive Statistics of the Total Score and Factor (dimension) Score of Each Scale}

As can be seen from Table 1 that the scores of PTM, IRI and MDQ of this group are all in the middle level (Carlo \& Randall, 2002; Han et al., 2013; Lu, 2015) and the social support is in the high level (Xiao \& Yang, 1987).

Table-1. Descriptive analysis of total score and each dimension (subscale) of 4 scales $(\mathrm{n}=1109)$.

\begin{tabular}{lcccc}
\hline Subscale (factor) & M & SD & Min & Max \\
\hline Total score of PTM & 53.8 & 29.1 & 23.0 & 102.0 \\
\hline Open prosocial behavior (ONPB) & 8.9 & 4.9 & 4.0 & 18.0 \\
Anonymous prosocial behavior (ASPB & 12.1 & 6.9 & 5.0 & 22.0 \\
\hline Altruistic prosocial behavior (ACPB) & 11.6 & 6.3 & 5.0 & 24.0 \\
Compliant prosocial behavior (CTPB) & 4.4 & 2.4 & 2.0 & 10.0 \\
Emotional prosocial behavior (ELPB) & 9.4 & 5.2 & 4.0 & 20.0 \\
Emergent prosocial behavior (ETPB) & 7.5 & 4.3 & 3.0 & 14.0 \\
\hline Total score of IRI & 65.5 & 14.4 & 28.0 & 79.0 \\
Empathy and care (EC) & 17.2 & 7.3 & 7.0 & 22.0 \\
Fantasy (FS) & 18.4 & 6.7 & 8.0 & 21.0 \\
Perspective taking (PT) & 14.2 & 4.6 & 3.0 & 14.0 \\
\hline Personal pain (PP) & 15.7 & 6.8 & 8.0 & 18.0 \\
Total score of MDQ & 39.4 & 10.2 & 20.0 & 61.0 \\
Moral defense (MD) & 17.4 & 4.1 & 9.0 & 19.0 \\
Favorable comparison (FC) & 10.6 & 2.5 & 7.0 & 15.0 \\
Responsibility attribution (RA) & 6.2 & 3.3 & 4.0 & 13.0 \\
Responsibility disengagement (RD) & 5.2 & 2.4 & 11.0 & 15.0 \\
\hline Total score of SSRS & 31.0 & 13.6 & 15.0 & 58.0 \\
Objective support (OS & 6.5 & 4.5 & 2.0 & 19.0 \\
Subjective support (SS) & 17.0 & 8.0 & 9.0 & 32.0 \\
\hline Utilization of support (US) & 6.6 & 2.6 & 4.0 & 13.0 \\
\hline
\end{tabular}

\subsection{Correlation Analysis between the Scores of Each Scale}

It can be seen from Table 2 that there is a significant positive correlation between the total score of PTM and IRI, MDQ , SSRS. 


\begin{tabular}{|c|c|c|c|c|c|c|c|c|c|c|c|c|c|c|}
\hline Variable & IRI & EC & FS & PT & PP & MD & FC & RA & RD & MDQ & OS & SS & US & SSRS \\
\hline 1.ONPB & $0.218^{* *}$ & $0.223^{* *}$ & $0.353^{* *}$ & $0.256^{* *}$ & $0.277^{* *}$ & 0.051 & 0.009 & 0.021 & 0.062 & 0.046 & $0.188^{*}$ & $0.184^{* *}$ & $0.173^{* *}$ & $0.231^{* *}$ \\
\hline 2.ASPB & $0.328^{* *}$ & $0.349^{* *}$ & $0.201^{* *}$ & $0.431^{* *}$ & $0.376^{* *}$ & $-0.128^{* *}$ & $-0.232^{* *}$ & $-0.106^{* *}$ & -0.083 & $-0.167^{* *}$ & 0.050 & $0.113^{* *}$ & 0.168 & $0.094^{* *}$ \\
\hline 3.ACPB & $0.301^{* *}$ & $0.286^{* *}$ & $0.266^{* *}$ & $0.409^{* *}$ & $0.380^{* *}$ & -0.014 & 0.006 & 0.033 & 0.067 & 0.016 & $0.185^{*} 0$ & $0.266^{* *}$ & $0.229^{* *}$ & $0.234^{* *}$ \\
\hline 4. СТPB & $0.262^{* *}$ & $0.354^{* *}$ & $0.251^{* *}$ & $0.388^{* *}$ & $0.334^{* *}$ & $-0.173^{* *}$ & $-0.157^{* *}$ & $-0.122^{* *}$ & -0.052 & $-0.163^{* *}$ & 0.033 & $0.235^{* *}$ & 0.038 & 0.021 \\
\hline 5.ELPB & $0.391^{* *}$ & $0.399^{* *}$ & $0.403^{* *}$ & $0.326^{* *}$ & $0.442^{* *}$ & $0.259^{* *}$ & $-0.080^{* *}$ & $-0.183^{* *}$ & -0.015 & $-0.197^{* *}$ & 0.024 & 0.045 & 0.0270 & 0.043 \\
\hline 6.ЕТPB & $0.421^{* *}$ & $0.408^{* *}$ & $0.390^{* *}$ & $0.500^{* *}$ & $0.338^{* *}$ & $-0.302^{* *}$ & $-0.229^{* *}$ & $-0.296^{* *}$ & $\begin{array}{c}- \\
0.123^{* * *}\end{array}$ & $-0.299^{* *}$ & 0.092 & 0.041 & 0.015 & 0.017 \\
\hline $\begin{array}{c}\text { 7.total score of } \\
\text { PTM }\end{array}$ & $0.369^{* *}$ & $0.317^{* *}$ & $0.325^{* *}$ & $0.379^{* *}$ & $0.449^{* *}$ & $-0.195^{* *}$ & $-0.134^{* *}$ & $-0.124^{* *}$ & -0.017 & $-0.162^{* *}$ & 0.054 & $0.155^{* *}$ & $0.102^{* *}$ & $0.174^{* *}$ \\
\hline
\end{tabular}

Note : ${ }^{*} P<0.05, * * P<0.01, * * * P<0.001$. 
3.3. Single Factor Analysis of Total Score of PTM

\subsubsection{Variable Assignment}

The possible situations (alternative answers) of 17 demographic classification variables that may affect the total score of PTM were assigned, and the results were shown in Table 3.

Table-3. variable assignments.

\begin{tabular}{|c|c|}
\hline 1.Grade & $0=$ Freshman, $1=$ Sophomore, $2=$ Junior, $3=$ Senior, $4=$ fifth year \\
\hline 2.Gender & $0=$ male, $1=$ female \\
\hline 3.Origin & $\mathrm{O}=$ city, $1=$ town,$\quad 2=$ country \\
\hline 4.Nationality & $\mathrm{O}=$ Han nationality, $1=$ ethnic minority \\
\hline 5. Do you have any religious beliefs? & $0=$ No, $1=$ Yes \\
\hline $\begin{array}{l}\text { 6. Are you or have you ever been a class } \\
\text { cadre? }\end{array}$ & $0=$ No, $1=$ Yes \\
\hline $\begin{array}{l}\text { 7. Are you working or have you ever } \\
\text { worked part-time? }\end{array}$ & $0=$ No, $1=$ Yes \\
\hline 8. School category & $\begin{array}{l}\mathrm{O}=\text { science and engineering, } 1=\text { liberal arts, } 2=\text { agriculture, } \\
3=\text { medicine, } 4=\text { sports, } 5=\text { art }, 6=\text { comprehensive }\end{array}$ \\
\hline 9. Major category & $\begin{array}{l}0=\text { science, } 1=\text { engineering, } 2=\text { agronomy, } 3=\text { management } \\
4=\text { medicine, } 5=\text { liberal arts, } 6=\text { sports, } 7=\text { art }\end{array}$ \\
\hline 10. academic performance & $\mathrm{O}=$ failed; $1=$ passed $; 2=$ medium; $3=$ moderate; $4=$ excellent \\
\hline 11. Are you only child or not? & $0=$ No, $1=$ Yes \\
\hline 12. Father' education level & $\begin{array}{l}\mathrm{O}=\text { primary school and below, } 1=\text { junior middle school, } 2=\text { Senior high } \\
\text { school or technical secondary school, } 3=\text { junior college, } 4= \\
\text { undergraduate, } 5=\text { Master degree or above }\end{array}$ \\
\hline 13. Mather' education level & $\begin{array}{l}0=\text { primary school and below, } 1=\text { junior middle school, } 2=\text { Senior } \\
\text { high school or technical secondary school, } 3=\text { junior college, } 4= \\
\text { undergraduate, } 5=\text { Master degree or above }\end{array}$ \\
\hline 14. Father' occupation & $\begin{array}{l}0=\text { business, } 1=\text { scientific researcher, } 2=\text { teacher, } 3=\text { medical staff, } \\
4=\text { labor worker, } 5=\text { management, } 6=\text { liberal professions }\end{array}$ \\
\hline 15. Mather' occupation & $\begin{array}{l}0=\text { business, } 1=\text { scientific researcher, } 2=\text { teacher, } 3=\text { medical staff, } \\
4=\text { labor worker, } 5=\text { management, } 6=\text { liberal professions }\end{array}$ \\
\hline 16. Family monthly income & $\begin{array}{r}0=0 \text { to } 4000 \text { yuan, } 1=5001 \text { to } 8000 \text { yuan, } 2=8001 \text { to } 12000 \text { yuan, } \\
3 \geq 12001 \\
\text { yuan }\end{array}$ \\
\hline $\begin{array}{l}\text { 17. Are you or have you ever been in } \\
\text { love }\end{array}$ & $0=$ No, $\quad 1=$ Yes \\
\hline
\end{tabular}

\begin{tabular}{lcc} 
Table-4. single factor analysis of demographic variables that may affect the total score of PTM. \\
\hline Item & $\mathbf{R} / \boldsymbol{T} / \boldsymbol{F}$ & $\boldsymbol{P}$ \\
\hline 1. Age & -0.056 & 0.160 \\
2. Grade & -9.479 & $<0.001$ \\
3. Gender & -15.106 & $<0.001$ \\
4. Origin & 4.945 & $<0.001$ \\
5. Nationality & -12.643 & $<0.001$ \\
6. Do you have any religious beliefs? & -25.426 & $<0.001$ \\
7. Are you or have you ever been a class cadre? & -11.317 & $<0.001$ \\
8. Are you working or have you ever worked part- & -22.232 & $<0.001$ \\
time? & & \\
9. School category & -1.129 & 0.325 \\
10. Major category & 4.890 & $<0.001$ \\
11. academic performance & 1.278 & 0.429 \\
12. Only child or not? & -3.780 & $<0.001$ \\
13. Father' education level & 1.269 & 0.334 \\
14. Mather' education level & 1.672 & 0.288 \\
15. Father' occupation & 0.837 & 0.566 \\
16. Mather' occupation & 0.681 & 0.713 \\
17. Monthly household income & -24.488 & $<0.001$ \\
18. Are you or have you ever been in love & -21.123 & $<0.001$ \\
\hline
\end{tabular}




\subsubsection{Single Factor Analysis of (for) Demographic Variables of the Total Score of PTM}

It can be seen from Table 4 that 7 items such as age, school category, academic performance, father's education level, mother's education level, father's occupation and mother's occupation, have no statistic meaning on the total score of PTM (r=-.056, $P=.160 ;|t| /|F|=0.681$ to 1.672 , all $p>0.05$ ); While the other 11 items have significant effects on the total score of PTM $(|t| /|f|=3.780$ to 25.426, all $P<0.01)$.

\subsection{Multiple Stepwise Linear Regression Analysis of Factors Related to Prosocial Behavior among College Students}

Taking the total score of PTM as dependent variable and the total scores of IRI, SSRs and MDQ, as well as the above 11 demographic variables with significant effects on the total score of PTM as independent variables, multiple stepwise linear regression was carried out within the 95\% confidence interval.

From Table 5, it can be found that 10 factors such as IRI total score, SSRs total score, nationality, religious beliefs, part-time job, grade, origin, love experience, major category and gender are positively correlated with PTM total score $(\beta=0.115$ to $0.708, P<0.05)$; two factors such as family monthly income and MDQ total score are negatively correlated with PTM total score $(\beta=-.352,-0.577$; both $P<0.01)$.

Table-5. multiple stepwise linear regression analysis of factors related to prosocial tendency among undergraduates.

\begin{tabular}{|c|c|c|c|c|c|c|}
\hline Dependent Independent & \multicolumn{2}{|c|}{$\begin{array}{l}\text { Regression } \\
\text { coefficient }\end{array}$} & \multirow[t]{2}{*}{$\boldsymbol{\beta}$} & \multirow[t]{2}{*}{$t$} & \multirow[t]{2}{*}{$P$} & \multirow[t]{2}{*}{$\boldsymbol{R}_{a d j}^{2}$} \\
\hline Variable & $\mathrm{B}$ & $\mathrm{SE}$ & & & & \\
\hline Total score & 0.746 & 0.088 & 0.708 & 6.148 & $<0.001$ & 0.533 \\
\hline of PTM Total score of IRI & & & & & 0.536 & \\
\hline Total score of SSRS & 0.373 & 0.063 & 0.581 & 4.963 & $<0.001$ & \\
\hline Grade & 0.383 & 0.077 & 0.197 & 5.058 & $<0.001$ & \\
\hline Part time job & 0.443 & 0.091 & 0.241 & 2.557 & 0.011 & \\
\hline Nationality & 0.246 & 0.055 & 0.115 & 2.295 & 0.020 & \\
\hline Religious beliefs & 0.309 & 0.117 & 0.153 & 2.475 & 0.013 & \\
\hline Origin & 0.247 & 0.072 & 0.127 & 2.197 & 0.028 & \\
\hline Love experience & 0.382 & 0.059 & 0.188 & 2.134 & 0.031 & \\
\hline Major category & 0.273 & 0.065 & 0.169 & 3.718 & $<0.001$ & \\
\hline Gender & 0.446 & 0.074 & 0.239 & 2.692 & 0.007 & \\
\hline $\begin{array}{l}\text { Family monthly } \\
\text { income }\end{array}$ & -0.475 & 0.078 & -0.352 & -2.887 & 0.004 & \\
\hline Total score of $\mathrm{MDQ}$ & -0.462 & 0.081 & -0.577 & -3.988 & $<0.001$ & \\
\hline
\end{tabular}

\section{DISCUSSION}

The total scores of PTM, IRI, MDQ and SSRI are (53.8 \pm 29.1), (65.5 \pm 14.4$),(39.4 \pm 10.2),(31.0 \pm 13.6)$, which is consistent with the previous study (An, Geng, \& Chen, 2017; Gao, Song, \& Chi, 2020; Lu, 2015; Sun et al., 2017; Xiu, 2018). It is suggested that the students in this group generally get high level of social support, and their prosocial behavior tendency, empathy ability and moral disengagement are at the intermedius level.

The results of multiple stepwise linear regression showed that 10 factors such as IRI total score, SSRs total score, nationality, religious beliefs, part-time job, grade, origin, love experience, major category and gender are positively correlated with PTM total score, while two factors such as monthly family income and MDQ total score are negatively correlated with PTM total score.

Empathy is a positive correlated factor of prosocial behavior tendeency, which has been supported by a large number of empirical studies (An et al., 2017; Zhu \& Li, 2005). Scholars have put forward a variety of related theoretical hypotheses. Hoffman (2000) points out that empathy is one of the important motivations of prosocial behavior, the precondition of prosocial behavior; Batson, Daniel, Cynthia, Shaw, and Klein (1995) think empathy which can build emotional experience similar to others and the general connection with others' welfare is the source 
of prosocial behavior; Nancy, Ivanna, Bridget, Stephanie, and Amanda (1999) think empathy is the motive basis for sympathy for others, and the effect of empathy is to achieve helping others through such model as "empathysympathy-social behavior". To sum up, empathy can be said to be the motivation source of prosocial behavior.

Social support is positively correlated with prosocial behavior, which is consistent with the results of previous research (Guo, 2018). Many scholars believe that social support influences prosocial behavior through self-concept. For example, Lin believes that individuals will encounter more or less difficulties in the process of growing up. If they get sufficient social support, they will have a sense of trust in others and society, feel their status and roles in society, participate more in interpersonal communication and collective activities, play their roles and make postive contribution, and obtain more recognition from others, in order to enhance their self esteem and self-confidence (Lin \& Yeh, 2014). Lin Healy believes that social support plays an indirect role in prosocial behavior through prosocial reputation: Actors first establish prosocial reputation through prosocial behavior, and prosocial reputation generates external incentive effect on actors through indirect reciprocity and peer selection, and generates internal incentive effect on actors through self-concept, thus promote their prosocial behavior (Ferm \& Deborah, 2013).

The total score of MDQ negatively predicts prosocial behavior tendency, which is consistent with the results of previous study (Lu, 2015). Moral disengagement is a cognitive tendency in the process of making individuals redefine their own behavior and minimize their responsibility in the consequences of behavior, so as to reduce the pain caused by behavior. Moral disengagement can make the individual reasonably separate the internal moral standards from guilt and self blame caused by immoral behavior, which reduces the self-restraint of morality, thus increases immoral behavior and reduces responsible prosocial behavior (Bandura, 1985).

This study also find that college students' prosocial behavior is significantly associated with a number of demographic variables.

First of all, the prosocial behavior tendency of girls is more obvious than boys, which is consistent with the research results of Xia and $\mathrm{Li}$ (2016), Lei, Nie, and Liu (2015) and Lei et al. (2015). The gender difference of prosocial behavior is not only shown in college students (Lei et al., 2015; Wang \& Bao, 2015; Xia \& Li, 2016) but also in primary school students (Feng, Zhang, \& Zhang, 2014) and teenagers (Geng, Han, \& Ye, 2012). It can be seen that it is a stable gender difference. Whether it is caused by biological factors such as genes or psychosocial factors such as gender role standards remains to be solved by follow-up studies.

Secondly, grade, part-time job and love experience can positively predict prosocial behavior tendency. Compared with lower grades, the prosocial tendency of higher grades is more obvious, which is consistent with the results of previous research (Geng et al., 2012; Sun et al., 2017) suggesting that the university stage is an important period for the development of prosocial behavior. Since there is no significant correlation between age and the total score of PTM, prosocial behavior is not naturally improved with physiological maturity, but the result of socialization, which needs strong social cognition, moral internalization and moral externalization ability (Ding \& Ye, 2013; Luo \& Bo, 2016). Only when an individual has strong moral internalization ability, can he make value judgment on the prosocial information he inputs, internalize the corresponding thoughts and concepts purposefully and selectively, carry out self selection, self reflection and self-education, internalize the corresponding moral requirements and behavior norms into his own consciousness, and form certain prosocial values. Under the influence of internal moral emotions and values, they have the motivation of external prosocial behavior, and use their willpower to implement the corresponding prosocial behavior (Gao, Ji, \& Zhang, 2020). College students are in the gradually matural stage of cognitive, emotion, personality and other psychological quality, with a strong need to understand, participate in and contribute to society. Through social practice activities (such as part-time work), gradually deepen the understanding of the society, form the correct social emotion, internalize social ethics, enhance 
the desire to serve and contribute to society, and then produce more and more prosocial behavior. Love experience can be said to be a special social practice, with a high degree of personal involvement, which has a far-reaching impact on the development of individual social cognition and social emotion (Feng et al., 2014) and indirectly affects the development of prosocial behavior.

Third, major category has a significant impact on prosocial behavior tendency, consistent with the results of previous research $(\mathrm{Lu}, 2015)$ which may be due to the different understanding of prosocial behavior among college students of different majors. Generally speaking, liberal arts students have more opportunities to contact society, have deeper understanding of prosocial behavior, and are more likely to identify with the social value of prosocial behavior.

Fourth, monthly family income negatively predicts the prosocial behavior tendency of college students, the prosocial behavior tendency of minority students is more obvious than that of Han students, and the prosocial tendency of rural students is significantly obvious than that of students from town or city, which is consistent with the research results of Yue and $\mathrm{Li}$ (2010); Davis (1980) and Xia and Li (2016). The reason is the empathy and social responsibility aroused by the weak effect (Yue \& Li, 2010). As a vulnerable group, the low-income people have to help each other, cooperate, exchange what they need and carry out other prosocial behaviors, in order to better alleviate the financial difficulties and resource shortage. At the same time, the interpersonal circle also helps them reduce the sense of isolation. Compared with the Han nationality, the living environment (conditions) of most ethnic minorities being worse, belonging to vulnerable groups, they must be closely united and cooperate with each other in order to live smoothly. Compared with students from town and city, rural stuendets' living environment (conditions) is worse. belonging to vulnerable groups, rural people must be closely united, mutual assistance and cooperation in order to live smoothly.

Finally, religious beliefs positively predict prosocial behaviors tendency, and the prosocial behavior tendency of students with religious beliefs is more obvious than that of students without religious beliefs, which is consistent with the results of previous studies (An, Zhang, \& Wang, 2018; Saroglou, Pichon, Trompette, Verschueren, \& Dernelle, 2011). "Supernatural monitoring hypothesis" (Stéphane, Piff, \& Willer, 2013) holds that religious beliefs play a monitoring role in people's behavior. The higher the degree of religious belief, the more supernatural beliefs individuals will feel and feel supervised and evaluated by supernatural forces, thus show stronger public selfawareness and social approval. Galen, Smith, Knapp, and Wyngarden (2011); Galen (2012) also pointed out that those with high level of religious beliefs are better at internalizing the religious doctrine of "truth, goodness and beauty" into their own moral standards, expressing higher compassion and moral level, and promoting them to produce more prosocial behaviors.

\section{REFERENCES}

An, L., Geng, Y., \& Chen, J. (2017). The relationship between empathy and prosocial behavior of university students. China Journal of Health Psychology, 25(9), 1369-1371.

An, L., Zhang, S., \& Wang, H. (2018). College Students' religiosity, gratitude, interpersonal forgiveness and pro-social behavior. Chinese Journal of Clinical Psychology, 26(3), 570-574.

Antonio, Z., Guido, A., Bernadette, P. L. K., Concetta, P., Michela, M., Rosalba, C., \& Gian, V. C. (2014). The relation between prosociality and self- esteem from middle adolescence to young adulthood. Personality and Individual Differences, 63, 2429.Available at: https://doi.org/10.1016/j.paid.2014.01.041.

Bandura, A. (1985). Social foundations of thought and action: A social cognitive theory (Vol. 10). Englewood Cliffs, New Jersey: Prentice Hall. 
Batson, C., Daniel, T., Cynthia, L., Shaw, L. L., \& Klein, T. R. (1995). Information function of empathic emotion: Learning that we value the other's welfare. Journal of Personality and Social Psychology, 68(2), 300-313.Available at: https://doi.org/10.1037/0022-3514.68.2.300.

Carlo, G., \& Randall, A. (2002). The development of a measure of prosocial behaviors for late adolescents. Journal of Youth and Adolescence, 31(1), 31-44.

Cohen, J. (1992). Statistical power analysis. Curr Direct Psychol Sci, 1(2), 98-101.

Cong, W. (2008). Research on the types of prosocial behavior of college students. Nanjing: Nanjing Normal University.

Davis, M. H. (1980). A multidimensional approach to individual differences in empathy. JSAS Catalog of Selected Documents in Psychology, 10, 85 .

Ding, J., \& Ye, X. (2013). Cultivation of college students' prosocial behavior based on internalization and externalization. Innovation and Entrepreneurship Education, 4(3), 16-18.

Eisenbe, R., \& Miller, P. (1987). The relation of empathy to prosocial and related behaviors. Psychological Bulletin, 101(1), 91-1 19.

Feng, C., Zhang, Y., \& Zhang, S. (2014). A study on the prosocial behaviors of primary school students in context of peer exclusion. Journal of Chengdu Normal University, 34(4), 57-61.

Ferm, L.-H., \& Deborah, A. S. (2013). Nice guys finish last and guys in last are nice: The clash between doing well and doing good. Social Psychological and Personality Science, 4(6), 692-698.Available at: https://doi.org/10.1177/1948550613476308.

Galen, L. W., Smith, C. M., Knapp, N., \& Wyngarden, N. (2011). Perceptions of religious and nonreligious targets: Exploring the effects of perceivers' religious fundamentalism. Journal of Applied Social Psychology, 41(9), 2123-2 143.Available at: https://doi.org/10.1111/j.1559-1816.2011.00810.x.

Galen, L. W. (2012). Does religious belief promote prosociality? A critical examination Psychological Bulletin, 138(5), 876906.Available at: https://doi.org/10.1037/a0028251.

Gao, F., Song, X., \& Chi, X. (2020). The mediating effect of sense of purpose in life between social support and suicide attitude in a college of Jinan City. Medicine and Society, 33(1), 120-124.

Gao, L., Ji, W., \& Zhang, X. (2020). The influence of moral acceptance of school atmosphere on college students' moral behavior and immoral behavior. Campus psychology, 18(1), 21-25.

Geng, Y., Han, X., \& Ye, Q. (2012). The relationship between gender, humanity attitude and adolescents' empathy and prosocial behavior. Journal of Zhengzhou University (Medical Sciences), 47(1), 43-46.

Guo, Y. (2018). Relationship of social support and prosocial behavior of college students: A mediating role of interpersonal trust. Henan Social Sciences, 28(6), 112-116.

Han, W., Ye, M., \& Leng, Y. (2013). Revision and verification of Chinese mainland version of interpersonal response scale. Journal of Southeast University (Philosophy and Social Science), 15(S1), 47-52.

Hoffman, M. (2000). Empathy and moral development: Implications for caring and justice. Cambridge: Cambridge University Press.

Hu, Y. (2012). Research on limitations of investigation into mental health condition of college freshmen with SCL-90. Journal of Changchun University, 22(4), 444-447.

Jin, P., Sun, G., \& Chen, Q. (2013). Research on the relationship between prosocial behavior and adaptability of college students. Economic Herald, 6(5), 76-77.

Lei, J., Nie, Y., \& Liu, L. (2015). The relationship between moral self-concept and pro-social behavior tendencies of college students. Journal of Guangzhou University (Social Science Edition), 14(6), 74- 77.

Li, Y., \& Luo, D. (2013). Research on the positive emotion experience of cooperative prosocial behavior in college students. Journal of Chongqing University (Social Science Edition), 19(4), 177-182. 
Li, Q., Wang, L., \& Tian, Y. (2018). Research on the relationship between empathy, social responsibility and prosocial behavior of College Students. Modern Communication, 7(13), 107-109.

Liang, Y., \& Hou, M. (2014). The influence of prosocial tendency on implicit aggression: Under the stimulation of different levels of violence. Theory Research, 4(11), 93-100.

Lin, C.-C., \& Yeh, Y.-C. (2014). How gratitude influences well-being: A structural equation modeling approach. Social Indicators Research, 118 (1), 205-2 17.Available at: https://doi.org/10.1007/s11205-013-0424-6.

Lu, Y. (2015). Research on the current situation of college students' moral disengagement. Journal of Taiyuan Normal University (Social Science Edition), 14(1), 121-124.

Luan, X., \& Chen, C. (2020). A study on the influence of prosocial motivation on innovation behavior: Taking transposition thinking as intermediary variable. Operation and Management, 5, 18-22.

Luo, S., \& Bo, Y. (2016). The influence of social perception on prosocial behavior of college students. Education Modernization, 34, 232-233.

Mo, M., Yang, Y., \& Xu, X. (2015). Influence of pro-social motivation on internet addiction: Chain mediating effect of basic psychology needs. Journal of Shaoyang University (Social Science Edition), 14(5), 114-120.

Nancy, E., Ivanna, K. G., Bridget, C. M., Stephanie, A. S., \& Amanda, C. (1999). Consistency and development of prosocial dispositions: A longitudinal study. Child Development, 7O(6), 1360-1372.Available at: https://doi.org/10.1111/14678624.00100 .

Saroglou, V., Pichon, I., Trompette, L., Verschueren, M., \& Dernelle, R. (2011). Prosocial behavior and religion: New evidence based on projective measures and peer ratings. Journal for the Scientific Study of Religion, 44(3), 323-348.Available at: https://doi.org/10.1111/j.1468-5906.2005.00289.x.

Shi, L., Huang, S., Zhuo, L., Wu, X., Zhao, H., \& Gen, D. (2013). Study on the reference value, reliability and validity of SCL-90 scale for college students. Chinese Journal of School Health, 34(2), 223-224.

Stéphane, C., Piff, P. K., \& Willer, R. (2013). For whom do the ends justify the means?: Social class and utilitarian moral judgment. Journal of Personality and Social Psychology, 104(3), 490-503.Available at: https://doi.org/10.1037/a0030931.

Sun, F., Lin, L., \& Dai, M. (2017). Autistic traits, empathy and theory of mind of college students with different level of prosocial behaviors. Journal of SUN YAT-SEN University (Medical Sciences), 38(6), 938-943.

Teng, Y. (2017). The application of cluster analysis and discriminant analysis in the results of college students' SCL-90 test. Chinese Journal of Social Mechine, 34(5), 460-462.

Wang, M., \& Chen, H. (2003). The relationship between academic performance, prosocial behavior, peer-acceptance, peerrejection among teenagers. Journal of Psychology Science, 26(6), 1130-1131.

Wang, L., \& Bao, H. (2015). Case study on the influencing factors and characteristics of prosocial behaviors among university students. Journal of Shenyang Institute of Engineering (Social Sciences), 11(1), 136-140.

Xia, M., \& Li, F. (2016). Analysis on the current situation of the prosocial motivation and behavior of "post-90s" college students. The Party Building and Ideological Education in Schools, 4, 9-12.

Xiao, S., \& Yang, D. (1987). The effect of social support on physical and mental health. Chinese Mental Health Journal, 1(4), 183187.

Xiu, W. (2018). The current situation, attribution and countermeasures of "post-95" College Students' prosocial behavior. Journal of Mudanjiang College of Education, 9, 43-45.

Yue, G., \& Li, W. (2010). The weakness leads to prosocial behavior -An empirical study from poor college students. Journal of Nankai University (Philosophy and Social Sciences), 3, 63-69.

Zhang, H., \& Xu, J. (2012). Modern statistics in psychology and education. Beijing: Publishing Group of Beijing Normal University. 
Zhang, J., \& Zhang, X. (2013). Chinese college students' SCL-90 scores and their relations to the college performance. Asian Journal of Psychiatry, 6(2), 134-140.

Zhang, Z., \& Jia, M. (2013). Relationships between daily affect and customer-oriented service behavior at work: The moderating role of prosocial motivation. Forecasting, 32(6), 8-14.

Zhang, J. (2013). An empirical study on the influencing factors of college students' prosocial behavior. Journal of Qingyuan Polytechnic, 1O(1), 77-81.

Zheng, L., \& Liu, X. (2013). Prosocial behavior of college students: Structural equation model of intervening psychological crisis. Journal of Statistics and Informaton, 28(5), 100-106.

Zhong, W., \& Li, l. (2009). Research on the consruction of new norm of SCL-90 for Chinese college students [J]. Chinese Journal of School Doctor, 23(3), 251-256.

Zhu, D., \& Li, D. (2005). Moral reasoning, empathetic response, and prosocial behavior: Their interrelations in middle school students. Journal of Psychological Science, 28(5), 1231-1234.

Online Science Publishing is not responsible or answerable for any loss, damage or liability, etc. caused in relation to/arising out of the use of the content. Any queries should be directed to the corresponding author of the article. 